\title{
The Benefits of Oral Reflection: The Use of Oral Reflective Action Learning Sets and Discussion Groups with Post Graduate Student Teachers
}

\author{
Melissa Mantle \\ Institute of Sport, University of Chichester, Chichester, United Kingdom
}

\section{Email address:}

m.mantle@chi.ac.uk

\section{To cite this article:}

Melissa Mantle. The Benefits of Oral Reflection: The Use of Oral Reflective Action Learning Sets and Discussion Groups with Post Graduate Student Teachers. International Journal of Secondary Education. Vol. 7, No. 1, 2019, pp. 11-16.

doi: $10.11648 /$ j.ijsedu. 20190701.13

Received: January 25, 2019; Accepted: March 14, 2019; Published: April 3, 2019

\begin{abstract}
The prime aim of this paper is to test the effectiveness of an oral reflective learning strategy that was introduced to a group of post graduate student teachers based within higher education, in order to secure their learning and, in turn, their performance as a reflective practitioner and teacher. The study was designed to include discussion groups and action learning sets, which took place within the University setting, after a period of work based experience. The PGCE cohort of 30 students were selected to take part in the reflective learning activities. A base line assessment of reflection took place, with the 'level' of reflection being assigned using Dewey's stages of learning (suggestion, problem solving, hypothesis, reasoning and testing) to ascertain which approach (discussion groups of action learning sets) were most effective. The results, following a series of groups and sets, showed the level of reflection increased in both activities but a more detailed level of reflection occurred in the action learning sets, providing self-generated reflective responses securing a greater understanding of the complexities of the situation. Thus, those involved with teacher training should note: oral reflective learning strategies are a useful tool to increase a meaningful connection to experience.
\end{abstract}

Keywords: Reflection, Action Learning Sets, Discussion Groups, Narrative

\section{Introduction}

Reflective learning allows students to process what they learned over the course of an experience and ultimately improves student performance. However, reflective learning is difficult to master. Reflective learning enables students to explore and challenge their own knowledge and to contextualise new learning. Given time and opportunity reflective learning can enhance learning but the correct blend of activities has to be appropriate for the learners. This research worked with post graduate student teachers to create the most effective tool for reflecting by introducing a reflective learning strategy.

Defining reflection and why it is important in learning

Bloom [1] portrays reflection as a complex and 'higher' form of learning by citing reflection as a definition for the sixth level 'evaluation' of his taxonomy of learning. Although I accept Bloom's classification as a helpful structure to understand the complexity of learning, the taxonomy is rigid and one dimensional with types of learning categorised rather than linking to each other, but for the purposes of this study it provides support for the importance of reflection as a form of learning.

Although Bloom considers reflection important, there is no single definition but there are various explanations suggesting the meaning of reflection. Dewey [2] views reflection as an active, persistent and careful consideration of an event that is likely to initiate change, creating a connection between something that has been completed and a future event. Moon [3] views reflection as a way to 'learn from, learn that, learn to do and learn to be', with Rodgers [4] seeing reflection as a meaning-making process, that is systematic, and requires interaction with intellectual and personal growth. Dewey's [2] original thoughts show that reflection includes a feeling of perplexity, hesitation and doubt. Dewey associates reflection with asking questions 
about an experience and he provides a framework for the reflection process. He suggests an individual learns from reflection through a stage-by-stage thought process that turns an experience into learning. He proposes reflection is a process where an individual stops, reviews or looks back and then tries again in order to improve a skill or gain additional knowledge and suggests an individual should be openminded, responsible and wholehearted [5].

Dewey's original work focuses on reflection as a process, a concept many other authors have reconsidered and developed to call critical reflection. Schön and Argyris's [6] double loop theory in particular the 'governing variable' I believe helps to explain the difference between a simple process of evaluation /reflection and critical reflection.

In my opinion, reflection that focuses on solving one problem without the consideration of 'other' factors can be associated with Dewey reflection. Reflection that does consider 'other' factors via the 'governing variable' is critical reflection. According to the literature the 'other' factors include: the individual's views or values of a previous experience, the importance of additional factors such as perception, personal habits, social pressure [7-8], their 'emotional state' [3], how the individual assigns meaning [9], or makes sense [10], all of which may result in a change in behaviour [11] and is referred to as critical reflection.

As an educator within higher education, my aim was to seek a way to enable students to critically reflect on their experience in order to enhance learning. Mantell and Scragg [12] and Sellars [13] suggested that students should be offered a broad range of opportunities, so with this work in mind, I looked to select appropriate 'tools' to encourage the students to reflect.

Parsons and Stephenson [14] highlight a concern that reflection is often a form of evaluation, often descriptive with helpful hints of how to cope in the future but may not be sufficient to ensure experiential learning. Oral reflection or the opportunity to verbalise thoughts may be an appropriate tool to move the student evaluation of a topic or learning toward a more critical form of reflection. After several years of experimenting I devised a reflective learning strategy that had a focus on verbal or oral reflection.

The term 'oral reflection' is used here to describe a form of reflection that involves an individual talking about their experience to either one or several other group members. The term oral reflection in this study does not refer to a casual conversation despite Malthouse and Roffey-Barentsen [15] advocating the use of all three distinctive parts to verbal reflective practice: the descriptive reflective conversation, the comparative reflective conversation and the critical reflective conversation. In this instance the term oral reflection relates to a critical reflective conversation, which attempts to demonstrate how the individual analyses their own position within the wider context of cultural, social and political agendas as the critical reflective conversation enables an individual to challenge and question their learning.

Numerous studies [12, 16-18] identify oral reflection as a successful way to reflect. Oral reflection requires an audience, but the influence and type of audience is a key factor and can affect the type of discussion and extent of the reflection. McDrury and Alterio [18] imply the number of people listening impacts on the outcome of the 'story', and oral reflection within a discussion group where individuals are allowed to interrupt, support or contradict may limit the reflection. They suggest the discussion group or action learning set situation gives the story being told multiple perspectives. Each environment, discussion group or action learning set provides a different atmosphere in which to reflect and may result in varying levels of reflection [18].

This research gave consideration to these different ways of achieving reflection and indeed learning. Some students may wish to express values or feelings orally to a professional member of staff or a peer-group member or even a concerned family member (Norton [17]). However, in these instances the comments are often descriptive or random. Ghaye [16] feels the conversation or 'reflective discourse' is a crucial element of the reflection process and oral discussion provides the opportunity for the student to place the situation temporarily in context at that particular time and provides the opportunity for the speaker to make sense of their own thoughts.

\section{Method}

The reflective learning strategy for this study was designed to include two activities to encourage oral reflection: discussion groups and action learning sets (ALS). My objective was to establish which reflective learning activity achieved the most reflection.

A cohort of 30 post graduate student teachers gave their permission to participate in the study. The discussion groups consisting of 6 students per group, were included as an activity to provide the opportunity for oral but communal reflection. The justification for using discussion groups in this research was not to discover just 'what' the students were thinking but with questioning from others in the group establish how and perhaps why they came to that opinion [19]. The concept behind a discussion group was to create a situation where participants who had shared a similar experience could listen and respond to comments made by others in a relaxed, natural atmosphere and allow 'emic' or natural information to be gained. The students were asked to initiate the discussion and in most instances a student would start the discussion with a personal account. Other students were allowed to interrupt, ask questions or contradict the opinions of others if they wished. The 'topic' was chosen and instigated by the individual student.

Action learning sets were used to give each participant the chance to talk about their practice to an audience: an opportunity to articulate their learning. The ALS were included as an activity within the learning strategy to provide the opportunity for oral reflection without interruption but within a communal setting. ALS were established with 6 participants, each participant was given a defined period of time ( 5 minutes) to talk to the rest of the group, uninterrupted, about a personal topic. The other 
participants became a silent audience. This structured approach varied from the apparently random conversation of the discussion groups and gave the individual an opportunity to talk with no interruption. This created a silent audience which can have methodological issues as any life experience or story that is shared with an audience is always altered to fit the dynamics of the situation, possibly to produce a reaction from the peer group.

The action learning sets like the discussion groups provided time and space [20] in a busy schedule for the participants to stop and think about critical situations [21] and even acknowledge their learning [22]. The action learning sets were used to provide the opportunity [23] for participants to vent their frustration, emotion, be resistant to authority or acknowledge the value of a relationship or situation by giving an account of their personal experience.

I took a conscious decision to prevent questioning at the end of the ALS. This was to eliminate any inhibitions the students may have had concerning the content of their topics. I was attempting to maintain a consistent context and I felt by allowing questioning I would have altered the 'lens' or purpose of the explanation [24], which may have altered the thought process, the ultimate reflection and lead to several versions of the same account.

Evidencing reflection

In order to evidence if reflection had occurred in the oral activities, and ultimately confirm impact from the strategy, I used Dewey's framework to interpret the data (suggestion, problem solving, hypothesis, reasoning and testing: Dewey [2]; Skilbeck [25]) as shown:

'What do you think? [suggestion] I think I do both I personally think individual feedback is better [problem solving] um I know group things are beneficial but if you say you need to do this a little bit better or this they get it after that. I think everyone should be targeted [hypothesis]. I think if you are polite to them they will be polite to you - I think they will then do other things for you'. (F2 - Discussion Group - September)

My overall objective was to discover when the reflection occurred indicating which oral activity was most beneficial for reflection. I undertook a process of investigation that counted the number of times reflection occurred during each activity within the strategy. I was not concerned which participant had revealed their learning through reflection; I was just concerned with the effectiveness of the activity to achieve student reflection. The total number of times reflection had occurred during one type of activity indicated the type of reflective learning activity that produced the most reflection. With the research of others $[12,18,26]$ in mind, I analysed the data to detect any difference in the type or use of language between the ALSs and the discussion groups.

\section{Results}

\subsection{Emergent Data}

It was at this point of the analysis that I realised the detail in the student's story, this data were emergent and had not been predicted [27]. Each student had used a full and coherent 'narrative' to communicate with the audience, especially in the ALSs. It soon became evident that much of the student reflection was told as a detailed story. The extent of this detail was unexpected. Once I realised the relevance of narrative I started to review all the reflective learning activities to investigate oral storytelling and this became a secondary objective of the research.

McDrury and Alterio [18] believe storytelling opportunities such as a reflective conversation should be maximised. I am interested in and wished to gain a better understanding of the work of Clandinin and Connelly [26] who deliberately use storytelling as a vehicle for their research, with Clandinin stressing the power of narrative in the use of reflection throughout his studies. Hunt [20] suggests individuals need to share and reflect with others, not only on the 'how' or 'why' of practice but on myths and narratives of life experiences. The use of narrative is possibly one of the oldest forms of communication and stories are often regarded as a powerful and essential part of our communication [28], primarily as the story enables the individual to organise their thoughts into a logical order, perhaps by creating a beginning, middle and an end. The narrative is a vehicle for reflection because during the story the individual makes choices: what to include, what to leave out, where to place extra description, why highlight a particular point and so on. Oral reflection, because it is usually spontaneous, does not always incorporate narrative, but if narrative were to be used, I was interested to identify the range of detail in the narrative provided by the participant.

\subsection{The Impact of the Reflective Learning Activities}

The initial objective was answered as I identified that reflection occurred in all the oral activities by all students. I then analysed each reflective learning activity to identify the level of reflection. I followed the advice of Ghaye [16] in creating a 'toolbox' of methods through which to reflect and wished to contribute to practice with my own suggestions. The data from all oral activities demonstrated a 'superficial engagement' (Dewey's stages suggestion, problem solving, hypothesis) with the reflection process and the use of narrative. The ALSs showed all five stages (Dewey: suggestion, problem solving, hypothesis, reasoning and testing) and were more personal and generated topics relating to the individual and their personal experience. My initial analysis showed that the discussion groups produced descriptive accounts concerning whole-school issues. The ALS provided the opportunity for students to talk at length about their own learning and personal development. The students appeared to be comfortable talking about themselves and their own progress. The issues F6 raised were personal and contained an emotional context. Her narrative was in chronological order and contained an introductory section that framed the event. F6, like other participants, used the term ' $\mathrm{I}$ ' and was prepared to openly consider the role of school-based staff or school procedures. 
'[It's been a] huge learning curve for me for the past weeks. I was at a private school before and the learning objectives we told them [pupils] what we were doing but it wasn't really a problem if you meet them or you didn't. Whereas the school I'm at now, we have a cycle we have to follow and I kind of adapted that in C... and school planning. And it's so much better when you put 3 [learning objectives] on the board and you answer it however I do have a huge problem with learning objectives where I set them too high. I've got much better at pitching them but I have a habit of putting my lessons and outcomes too high hoping the kids [pupils] would come up to it but they very rarely do [mulling over]. So that is like personal expectations. I've learnt in some lessons [but in others] I've had to completely adapt a lesson in a minute because of the drill. I think everyone can play sport and that's when I've had mentor comments! I'm quite aware of what is working and what is not because it's quite apparent they are not the most talented bunch but I've got to start playing to their strengths and not what I want' [mulling over - unjustified conclusion]. (F6 - Action Learning Set - April)

The participants used the opportunity of the ALS to tell a prolonged, full and coherent narrative of their experience, which enabled the discovery of not only 'what' the students were thinking but also 'how and why' they had come to that decision. This supports the work of Kruegar and Casey [19], who highlighted the importance of giving students the time and space to consider how and why an action had been taken. This was not the case in the discussion groups, where the narrative was often interrupted and became disjointed with less consideration of detail.

I found it very interesting that the tape recordings of the ALSs had very few pauses. The speech was continuous with only a brief pause for breath. There were no deliberation pauses, just the occasional repetition of the sound 'umm...' until the story was re-joined and then completed. The story told was detailed and in chronological order. The students appeared to use the ALS to talk about an experience with the other group members. The participants used language and terminology that was familiar to the audience. There was little or no need to explain a term or phrase, the student just continued the story, almost expecting the peer group to follow the episode that was being explained. There was an expectation that everyone would fully understand, it was as if the participant took on the role of 'storyteller'.

The uninterrupted narrative found in the ALS data suggests that the ALS provided the opportunity for the student to extend the story beyond a brief summary. The narratives were detailed and descriptive, as shown in the following extract:

'It is a massive thing as you've got to be really concentrating on those two pupils and then you've got another 30 in the class [suggestion]. What do you kind of do with them? [problem solving] We got them playing $2 v 2$ with the Afghanistani boys playing each other' [continues to hypothesis]. (M1 - Action Learning Set - November)

The ALSs appeared to provide an opportunity for the student to question their own thoughts and beliefs, whereas the other oral reflective activity, the discussion group, enabled the individual to ask questions to the peer group. The discussion groups appeared to be useful for the students to 'introduce' a topic or concern but the discussion was often interrupted or altered by the views and opinions of others in the group. The discussion groups often produced more questions than answers. It was as if the students were seeking reassurance from the peer group. M7, F2 and F1 appeared to use the discussion group to ask a question directly to the other members of the group as shown when M7 asks: 'were the other three girls benefiting from the lesson?', F2 says: 'What do you think?' and F1 says: 'Do you have to have a framework that is whole school?':

'They kept the same 3 people with her all the time, obviously the $C B$ girl was getting involved all the time but were the other 3 girls benefiting from the lesson? [suggestion] '(M7 - Action Learning Set - April)

'Do you have to have a framework that is whole school? [suggestion] Can't you have a personal framework [hypothesis]. They know it's $\mathrm{Mr} X$ so they know how far they can push'. (F1 - Discussion Group - September)

In the discussion groups all but one of the participants selected a common or generic theme to discuss. This may have been an attempt to satisfy the perceived interest of the cohort by considering a topic that was relevant to the whole group. It could also indicate a fear of admitting any personal issue or concern directly related to the theme. It could be suggested that the participant was raising the issue to discover the reaction or understand the interpretations of the others. If the participant perceived the discussion to be positive and gain the empathy of the audience the student may proceed to admit a level of vulnerability.

I acknowledged the effect of the audience in the discussion groups and ALSs. The audience may have caused the participants to 'act' or tell a story for an effect or to signal an alternative or possibly controversial view. I found this 'acting' role was occasionally evident in the language or type of speech used. Fairclough [29] highlighted the different 'frames' of speech through the discourse used, for example interview style, everyday style, family style and how the various frames of conversation can produce very different topics. In this instance the students used an interview style of conversation even in the discussion groups and ALSs because they possibly felt slightly uncomfortable or at 'work' rather than totally relaxed in a home situation. In other words the students appeared to modify their speech according to the audience [30].

\section{Discussion}

The reflective learning activities provided an opportunity to tell a story, which gave both the listener and storyteller a visual picture of the experience. However, there was a delay between the actual event and the story being told. During this time delay the participant had time to recollect thoughts, emotions, value, and consider the language used. This 
elongated pause between the event and the oral storytelling possibly allowed the student time to reflect and place the narrative in context.

It soon became apparent that the participants were sharing their experiences in the form of a story. The narratives were focused on themselves and their classroom teaching and did not include any conceptual thinking. The content of the account was subject based. The student always used subjectspecific language and sometimes named the pupil involved, often providing a brief history of the child concerned. The participants often provided this background material before starting the narrative. We naturally create an order when we construct texts, but it is not evident if the storyteller will provide any necessary context to the story [31].

It was also interesting to note the students' use of a 'metadiscursive marker'. The students would mark a point of the story, move backwards in the narrative, before returning to the original point to continue the tale. The technique of moving back in time before moving forward was a common theme in all the oral reflective activities. Once the historical context had been provided, the story continued in chronological order with descriptive additions.

The narrative of both oral reflective learning activities contained both personal and detailed information and adds to Sellar's [13] belief that a teacher's 'personal practical knowledge' is narratively constructed. It was Clandinin and Connelly [26] who viewed the power of narrative, in both a positive and negative way, and I feel the participants were 'stretching' the reality of the story because they felt comfortable. The brief verbal stories resembled episodes or chapters of the student's life. I found the detail of the narrative very intriguing. The story always had a brief introduction when the scene was set and the issue was placed into context and the characters were usually introduced very early in the account as can be seen here: 'The pupils know where they stand, where I stand I'm not authoritative and I've got that boundary just right'. The children and context of managing behaviour have been introduced in the opening sentence. This was usually followed by a description of the character or an area of concern that brought the character to life in the mind of the audience such as: 'You have fun with them' provided an image of a good-natured environment. The participant then 'guided' the listener through the tale providing detail through all the stages of development. All events were clearly expressed such as 'I've developed a lot of cards with diagrams' as the participant left nothing to the imagination of the audience.

The level of detail enhanced the narrative and produced a more vivid image of the episode. The student may have felt the narrative was 'boring' or insignificant to an audience and therefore needed enhancement or the participant may be so engrossed in the storytelling exercise the finer details were a natural part of the account.

\section{Conclusion}

In summary, the overall objective was answered as I identified that reflection occurred in all the oral activities by all students. The narrative was used to reflect extensively by all the participants. The detail and complexity of the story varied between the reflective learning activities. The majority of the detailed narratives only occurred in the ALS. The participant would tell one narrative during one ALS and did not continue the same story across two reflective learning activities. There was never any mention or recall to a former ALS. Each narrative was an individual chapter of the participants' school experience. This gave the impression of a set of discontinuous units over the research period. The oral learning activities promoted the use of narrative, which may have promoted Dewey reflection. As a practitioner I now encourage the use of a story to initiate the reflection process. However, the student then needs time and preparation and in some cases guidance, to orally reflect. I felt that two or multiple conversations occurring in the discussion groups prevented an organised or structured reflection whereas the ALS encouraged more detailed critical reflection. This was shown to be correct as the ALSs as opposed to the discussion groups provided the most effective environment for Dewey reflection and I feel a more structured approach to the ALS would equate to more reflection and consequent learning.

\section{References}

[1] Bloom, B. (1956). Taxonomy of Educational Objectives. London: Longmans.

[2] Dewey, J. (1933). How we think: A Restatement of the Relation of Reflective Thinking to the Educative Process. London: Lexington Heath.

[3] Moon, J. (2010). Reflection in Learning \& Professional Development. London, New York: Routledge/Falmer.

[4] Rodgers, C. (2002). Defining Reflection: Another Look at John Dewey and Reflective Thinking. Teachers College Record 10 (4), 842-866.

[5] Farrell, P. (2004) School Psychologists. School Psychology International. 25:5-19.

[6] Schön, D. and Argyris, C. (1987). Theory in Practice: Increasing Professional Effectiveness. London: Jossey-Bass.

[7] Mezirow, J. (1983). 'Critical theory of adult learning and education'. In Tight, M. (Ed.), Education for Adults, Vol. 1. London: Croom Helm.

[8] Mezirow, J. (Ed.) (2000). Learning as Transformation: Critical perspectives on a theory in progress. San Francisco: JosseyBass.

[9] Moon, J. (2008). Critical Thinking. An Exploration of Theory and Practice. Abingdon, New York: Routledge.

[10] Boud, D., Keogh, R. and Walker, D. (2013). Reflection: turning experience into learning. London: Kogan Page.

[11] Osterman, K. F. and Kottkamp, R. B. (2015). Reflective Practice for Educators -Professional development to improve student learning. London, Corwin Press Inc. 
[12] Mantell, A. and Scragg, T. (2018). Reflective practice in social work. London: Sage.

[13] Sellars, M. (2017). Reflective practice for teachers. London: Sage.

[14] Parsons, M. and Stephenson, M. (2005). Developing Reflective Practice. Teachers and Teaching: theory and practice 11 (1), 95-116.

[15] Malthouse, R. and Roffey-Barentsen, J. (2013). Reflective practice in education and training. London: Sage.

[16] Ghaye, T. (2010). Teaching and Learning through Critical Reflective Practice. Oxon: Fulton Pub.

[17] Norton, L. (2018). Action research in teaching and learning: a practical guide to conducting pedagogical research in universities. Oxon: Routledge.

[18] McDrury, J. and Alterio, M. (2003). Learning through Storytelling. Using reflection and experience in higher education contexts. New Zealand, Palmerston North: The Dunmore Press Ltd.

[19] Kruegar, R. and Casey, M. A. (2015). Focus groups, a practical guide for applied research. London: Sage.

[20] Hunt, C. (2010). 'A step too far? From professional reflective practice to spirituality'. In Bradbury, H., Frost, N., Kilminster, S. and Zukas, M. (Eds.), Beyond Reflective Practice (pp. 155169). London: Routledge.
[21] Brockbank, A. and McGill, I. (2004). The Action Learning Handbook. Falmer: Routledge.

[22] Mertler, C. (2019). The Wiley handbook of action research in education. Chichester: Wiley-Blackwall.

[23] Fook, J. (2010). "Reworking the "critical" in critical reflection'. In Bradbury, H., Frost, N., Kilminster, S. and Zukas, M. (Eds.), Beyond Reflective Practice (pp. 37-51). London: Routledge.

[24] Knott, C. and Scragg, T. (Eds.) (2007). Reflective Practice in Social Work. Exeter: Learning Matters Ltd.

[25] Skilbeck, M. (1970). Dewey - Educational Thinkers Series. London: Macmillan.

[26] Clandinin, D. and Connelly, F. M. (2004). Narrative Inquiry. Experience and Story in Qualitative Research. San Francisco: Jossey-Bass Publications.

[27] Bold, C. (2012). Using narrative in research. London: Sage.

[28] Hammond, J. (1990). New Methods in RE Teaching - An Experiential Approach. Harlow: Oliver and Boyd.

[29] Fairclough, N. (1992). Discourse and Social Change. Oxon: Blackwell.

[30] Wetherall, M., Taylor, S. and Yates, S. J. (2015). Discourse as data, a guide for analysis. London: Sage.

[31] DeFina, A. and Georgakopoulou, A. (2019). The handbook of narrative analysis. Oxon: Wiley- Blackwall. 